\title{
Joint-preserving regenerative therapy for patients with early-stage osteonecrosis of the femoral head
}

\author{
Yutaka Kuroda $^{1 *}$, Shuichi Matsuda ${ }^{1}$ and Haruhiko Akiyama²
}

\begin{abstract}
Osteonecrosis of the femoral head is an intractable disease often occurring in patients aged 30-40 years that can cause femoral head collapse, pain, and gait disturbance. Background factors, including corticosteroid use, alcohol intake, and idiopathic causes, have been indicated. It is estimated that $70-80 \%$ of osteonecrosis patients experience femoral head collapse, for which total hip arthroplasty is considered the most effective treatment, even in young patients. Thus, there is a crucial need for developing a minimally invasive regenerative therapy as a preventive surgery for femoral head collapse: this has been an important area of research in the past decades. Core decompression, the most popular minimally invasive surgery for osteonecrosis of the femoral head, has been used for a long time; however, it has been insufficient to prevent femoral head collapse. For further improvement in therapeutic efficacy, cell transplantation and the use of artificial bone and growth factors have been proposed in addition to core decompression. Since 2000, newer therapies such as autologous bone marrow cell transplantation and the embedding of metal implant rods have been developed in Europe and the USA; however, these approaches have yet to become a global standard. This practical review summarizes applied state-of-the-art regenerative therapy-based core decompression. We introduce the clinical application of recombinant human fibroblast growth factor (rhFGF)-2-impregnated gelatin hydrogel for patients with precollapse osteonecrosis of the femoral head. Radiography and computed tomography have confirmed bone regeneration inside the femoral heads around the region of rhFGF-2 gelatin hydrogel administration. With further development, the minimally invasive method, which can be expected to promote bone regeneration in necrotic areas, could become a useful early-stage treatment for osteonecrosis of the femoral head. Patients can resume their daily routine soon after surgery, and the procedure is inexpensive. As such, it is a promising regenerative therapy that can be actively employed in osteonecrosis of the femoral head before femoral head collapse.
\end{abstract}

Keywords: Osteonecrosis, Femoral head, Regenerative therapy, Growth factor, Fibroblast growth factor, Clinical trial

\section{Background}

Osteonecrosis of the femoral head (ONFH) is a destructive disease of the hip joint caused by a critical decrease in the vascular supply to the femoral head. Several causative factors have been indicated, including corticosteroid use, alcohol intake, hypercoagulation, bone marrow fat embolisms, elevation of intraosseous pressure in the femoral head, and vascular endothelial dysfunction [1-4]. However, the pathogenesis of ONFH is poorly understood. ONFH often occurs in young adults who

\footnotetext{
* Correspondence: ykuromd@kuhp.kyoto-u.ac.jp

'Department of Orthopaedic Surgery, Graduate School of Medicine, Kyoto University, Shogoin, Kawahara-cho 54, Sakyo-ku, Kyoto 606-8507, Japan Full list of author information is available at the end of the article
}

are in their 30s, and it occurs bilaterally in approximately half of the cases. Steroid-induced ONFH is commonly encountered by orthopedic surgeons and in other medical departments (such as collagen disease, rheumatology, hematology, nephrology, transplant surgery, respiratory, dermatology, and ophthalmology departments) where steroid pulse therapies are performed. Thus, magnetic resonance imaging (MRI) can be performed for early diagnosis, especially for patients receiving steroid pulse therapy.

Core decompression, which is frequently used in Europe and the USA $[2,3,5]$, is a minimally invasive surgery; however, if the necrotic area is large, the effect of core decompression may be limited, and femoral head 
collapse often occurs regardless. This procedure is almost never performed in Japan, except for biopsy purposes. Other conventional joint-preserving therapies, such as trochanteric rotational osteotomy (the most common hip joint surgery in Japan) and vascularized bone grafts, are difficult, highly invasive, and entail several months of recovery before the patient can resume a daily routine. Considering the age at which ONFH commonly occurs, opting for such operations while the patient is still asymptomatic is difficult. Both the patients and surgeons have difficulty in deciding on a method and the timing of these operations.

Femoral head collapse occurs in $70-80 \%$ of ONFH cases, depending on the size and location [6,7]. After femoral head collapse, the ONFH site develops secondary osteoarthritis (OA), destroying both the femoral head and the acetabulum $[2,3,8]$. Total hip arthroplasty (THA) is considered an effective treatment for secondary osteoarthritis, even in young patients [3, 7]. As THA is invasive and requires a revision surgery, it is crucial to develop a minimally invasive regenerative therapy that can preserve the femoral head, thus preventing collapse. This has been a research focus for many years [2, 3, 9-11].

Cell therapy [12-16], proteins, and other bone substitutes $[9,17,18]$ have been proposed, and various types of cell therapies using autologous marrow cells or stem cells are already being attempted, though they have not yet become standardized. Non-cellular therapeutic strategies using growth factors have also been proposed; however, verification in animal experiments has made little progress, primarily because of the absence of an animal model for femoral head-specific necrosis $[9,19,20]$ and secondarily because of the lack of a technique to locally deliver the growth factor [21].

To help address this problem, we reported a new rabbit model in which early ONFH progresses to femoral head collapse and OA, similar to that in humans. While animal models of corticosteroid treatment alone do not develop the characteristics of advanced ONFH seen in humans [22], we applied a rabbit model of ONFH induced by a combination of methylprednisolone administration and vascular occlusion of the capital femoral epiphysis by electrocoagulation. The rabbits started to develop ONFH around 4 weeks after the ONFH procedure and established ONFH within 8 weeks [23]. In this model, we showed that a single local injection of recombinant human fibroblast growth factor (rhFGF)-2-impregnated gelatin hydrogel, which has superior slow-release characteristics, suppresses the progression of femoral head necrosis. To translate this research to humans, the clinical application of controlled release rhFGF-2 for precollapse ONFH patients was performed at the Department of Orthopaedic Surgery in Kyoto University Hospital starting in March 2013 [24]. In this review article, we present the local application of
rhFGF-2 in human ONFH and its clinical benefit compared to other treatments.

\section{Treatment strategy for ONFH}

Conventional surgical treatment, mainly core decompression, is used widely in Europe and the USA [2, 3, 5]; in contrast, in Japan, a variety of surgical osteotomy procedures have been performed. However, clinical results vary: the collapse rate of the femoral head was more than $70 \%$ in core decompression with precollapse ONFH in one study [13], while others have reported a collapse rate of $50 \%$ with rotational osteotomy [25]. A variety of surgical methods have also been reported, including free or vascularized methods with fibular and iliac bone grafts, allogeneic bone grafts, and bone cartilage transplantation (mosaicplasty); bone cement injection to the femoral head has also been reported, although it is not common. Currently, there is no consensus regarding the standard treatment (Fig. 1).

The use of MRI improves early diagnosis, especially in patients receiving steroid pulse therapy. Accordingly, the treatment target has emphasized aggressive early prevention of femoral head collapse. Core decompression alone is challenging [13, 26, 27]; therefore, cell transplantation and artificial bone or metal implants in the core site have also been attempted. In addition, a deliverable, growth factor-containing, bone-promoting substitute has also been proposed $[2,3,9,17,18]$.

\section{Osteotomy}

Over 40 years, various types of osteotomies have been performed for the treatment of ONFH. The concept of surgery consists of moving the necrotic region from the weight-bearing surface of the femoral head. These involve three-axis directions, varus-valgus, flexion-extension, and anterior-posterior rotation. These procedures are technically demanding and are popular in Asia, though less in other regions $[3,28]$.

\section{Bone grafting}

Various surgical techniques have been reported for the use of bone grafts for the treatment of ONFH. In the 1930s, Phemister first reported a surgical procedure of a non-vascularized bone graft from the tibia for the treatment of ONFH [28]. Since then, newer techniques such as the lightbulb and trapdoor non-vascularized bone graft have been used with good results [29]. Another technique for bone grafting is vascularized option. Vascularized fibular graft was introduced in 1979 and consists of a fibular graft together with its vascular supply and harvested directly into the necrotic lesion of the femoral head [28]. Vascularized fibular graft is one of the technically difficult orthopedic surgeries which require technique of microvascular surgery. More recently, the 


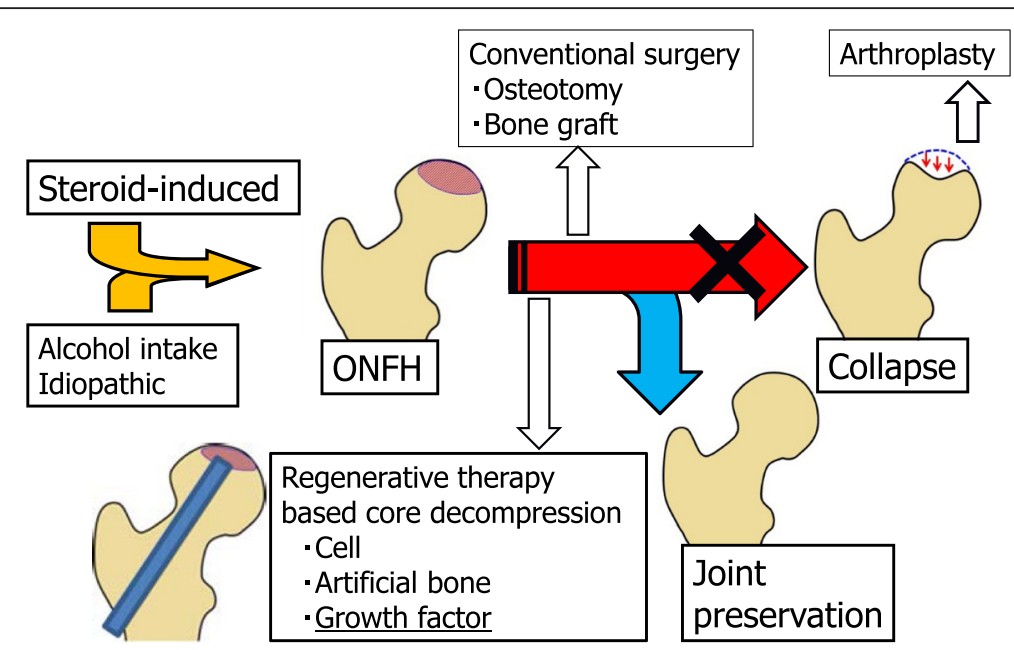

Fig. 1 Treatment strategy for osteonecrosis of the femoral head. Scheme of treatment strategy for osteonecrosis of the femoral head (ONFH) is shown. In daily clinical cases, even if a patient is diagnosed with ONFH, most cases experience femoral head collapse without surgical treatments and finally have to undergo total hip arthroplasty. The ultimate goal for ONFH therapy is to prevent femoral head collapse. Surgical alternatives for preservation include osteotomy and vascularized bone grafting, but the procedures are difficult, technically demanding, and require long-term hospitalization. Therefore, there has been a great desire for a minimally invasive regenerative therapy that can prevent femoral head collapse. Several regenerative treatment options, including cell or stem cell transplantation, artificial bone substitutes, and administration of growth and differentiation factors, have been recently reported

addition of biological reagents has demonstrated positive results [30].

\section{Pure conservative therapy}

A recent prospective, double-blind study showed that with conservative therapy using an oral bisphosphonate agent to prevent femoral head collapse, there was no difference in collapse progress between the placebo and treatment groups [31]. In Japan, novel clinical trials as a pure conservative therapy are performed and are registered to the public Japanese clinical trials registry, the University Hospital Medical Information Network (UMIN) Clinical Trials Registry. In recent years, bisphosphonates and parathyroid hormone have also started to be used to prevent collapse (UMIN000017582). In addition, for systemic lupus erythematosus patients undergoing steroid pulse therapy, a three-drug combination of the enzyme 3-hydroxy-3-methylglutaryl coenzyme A reductase inhibitor (pitavastatin), adenosine diphosphate receptor blocking antiplatelet (clopidogrel), and antioxidant (tocopherol) is co-administered (UMIN000008230). Other types of conservative treatment using an external device, such as hyperbaric oxygen therapy and extracorporeal shock wave lithotrity (UMIN000020197), have also been developed [32].

\section{Core decompression}

Core decompression is a minimally invasive surgery for ONFH dating back to the 1960s [28]. It was originally used to create a single large bone hole $>10$-mm diameter and had a high femoral head collapse rate. Over time, the method improved and now involves multiple bone holes of a smaller diameter $(3 \mathrm{~mm})$; this method has been popular since the $2000 \mathrm{~s}$. With the improved method, collapse rates are now $30 \%$ for precollapse ONFH [33]. To further improve therapeutic efficacy to prevent femoral head collapse, cell transplantation, artificial bone, and growth factors have been used (Fig. 2).

\section{Regenerative therapy-based core decompression Metal implants}

A preventive treatment involving the placement of cylindrical artifacts in the core decompression site has been developed in Europe and the USA. Such artifacts include implant rods made of Zimmer Trabecular Metal (porous tantalum, manufactured by Zimmer, Warsaw, IN, USA), which are available in both small and large diameters. Tsao et al. used a large-diameter rod in 113 joints from 97 patients with precollapse ONFH; over 4 years, 19 joints (19.6\%) underwent THA [34]. Similarly, Veillette et al. reported that of 48 joints from 42 patients, 16 (33.3\%) experienced a collapsed femoral head over 4 years [35]. In addition, Floerkemeier et al. reported that in 23 joints with $\mathrm{ONFH}, 13$ (56.5\%) required THA after an average of 1.45 years. In contrast to other studies, the outcome after core decompression combined with tantalum rod insertion was not superior compared to core decompression alone [36].

\section{Artificial bones}

$\mathrm{Yu}$ et al. reported that injectable calcium phosphate-based artificial bone $\left(\mathrm{CaSO}_{4} / \mathrm{CaPO}_{4}\right.$ composite) was used alone 

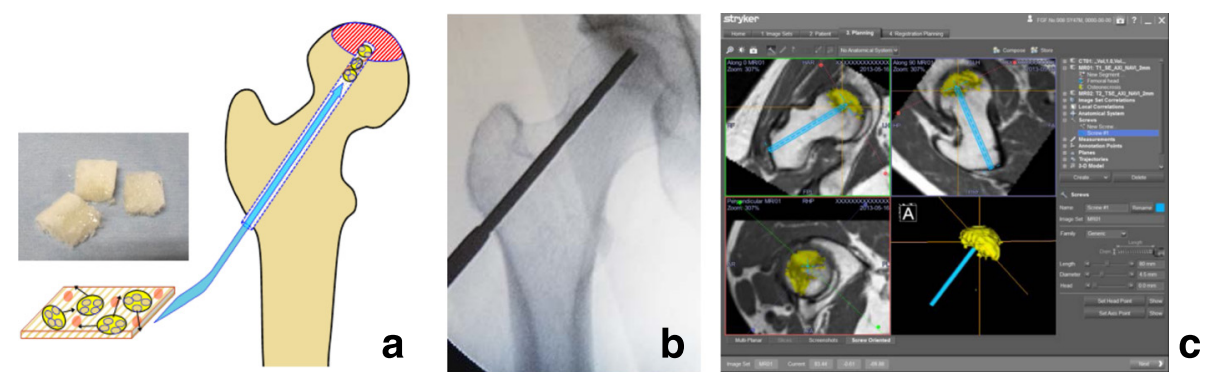

Fig. 2 Regenerative therapy using controlled release of recombinant human fibroblast growth factor. Schematic views and photographs of the surgical procedure using recombinant human fibroblast growth factor (rhFGF)-2-impregnated gelatin hydrogel for patients with precollapse stage of osteonecrosis of the femoral head (ONFH) are shown. a A schema of the surgical procedure administering the rhFGF-2 gelatin hydrogel. The rhFGF-2-impregnated gelatin hydrogel is embedded percutaneously over the lateral aspect of the femur near the level of the lesser trochanter. A small photograph on the left side shows the actual gelatin hydrogel, which is a superior slow-release carrier for growth factors. $\mathbf{b}$ A representative intraoperative fluoroscopic image at drilling. c A screenshot of the preoperative planning using navigation software is shown. The yellow area shows the area of ONFH. The surgeon planned the suitable route of drilling (blue screw)

Table 1 Joint-preserving regenerative therapy-based core decompression

\begin{tabular}{|c|c|c|c|c|c|c|}
\hline First author year/design & Technique & $\begin{array}{l}\text { Number of hips } \\
\text { (precollapse) }\end{array}$ & $\begin{array}{l}\text { Background factors } \\
\text { for ONFH (\%) }\end{array}$ & $\begin{array}{l}\text { Mean age } \\
\text { (years) }\end{array}$ & $\begin{array}{l}\text { Mean follow-up } \\
\text { (years) }\end{array}$ & Hip survivorship (\%) \\
\hline \multirow[t]{2}{*}{ Tsao [34] 2005/P } & $C D$ & \multirow[t]{2}{*}{94} & \multirow{2}{*}{$\begin{array}{l}\text { S 41, A 24, I 30, } \\
\text { others } 5\end{array}$} & \multirow[t]{2}{*}{43} & \multirow[t]{2}{*}{4.0} & \multirow[t]{2}{*}{80.4} \\
\hline & $\mathrm{TR}$ & & & & & \\
\hline \multirow[t]{2}{*}{ Veillette [35] 2006/R } & $C D$ & \multirow[t]{2}{*}{50} & \multirow{2}{*}{$\begin{array}{l}\text { S 45, A 3, I 26, T 10, } \\
\text { others } 16\end{array}$} & \multirow[t]{2}{*}{35} & \multirow[t]{2}{*}{4.0} & \multirow[t]{2}{*}{66.7} \\
\hline & $\mathrm{TR}$ & & & & & \\
\hline \multirow[t]{2}{*}{ Floerkemeier [36] 2011/P } & $C D$ & \multirow[t]{2}{*}{23} & \multirow[t]{2}{*}{ NR } & \multirow[t]{2}{*}{40} & \multirow[t]{2}{*}{1.4} & \multirow[t]{2}{*}{43.5} \\
\hline & $\mathrm{TR}$ & & & & & \\
\hline \multirow[t]{2}{*}{ Yu [37] 2015/P } & $C D$ & \multirow[t]{2}{*}{6} & \multirow[t]{2}{*}{ S 5, A 68, I 21, T 5} & \multirow[t]{2}{*}{48} & \multirow[t]{2}{*}{1.4} & \multirow[t]{2}{*}{50.0} \\
\hline & $\mathrm{CaSO}_{4} / \mathrm{CaPO}_{4}$ & & & & & \\
\hline \multirow[t]{2}{*}{ Hernigou [16] 2009/P } & $C D$ & \multirow[t]{2}{*}{534} & \multirow[t]{2}{*}{ S 19, SCD 31, I 28} & \multirow[t]{2}{*}{39} & \multirow[t]{2}{*}{13.0} & \multirow[t]{2}{*}{82.4} \\
\hline & BMMNC & & & & & \\
\hline Gangji [13] 2011/RCT & $C D$ & 11 & S 82, A 9, 19 & 45.7 & 5.0 & 27.3 \\
\hline \multirow[t]{2}{*}{ Gangji [13] 2011/RCT } & $C D$ & \multirow[t]{2}{*}{13} & \multirow[t]{2}{*}{ S 85, A 8, I 8} & 42.2 & 5.0 & 76.9 \\
\hline & BMMNC & & & & & \\
\hline Civinini [41] 2012/P & $C D, B M C$ & 30 & S 49, A 35, I 16 & 43.9 & 1.7 & 83.3 \\
\hline & $\mathrm{CaSO}_{4} / \mathrm{CaPO}_{4}$ & & & & & \\
\hline Yamasaki [42] 2010/R & $C D$ & 9 & S 22, A 44, I 33 & 49 & 2.4 & 0 \\
\hline & $\mathrm{HA}$ & & & & & \\
\hline Yamasaki [42] 2010/R & $\mathrm{CD}, \mathrm{BMMNC}$ & 27 & S 73, A 20, 17 & 41 & 2.4 & 56.7 \\
\hline & $\mathrm{HA}$ & & & & & \\
\hline Lieberman [17] 2004/P & $C D, F B G$ & 16 & S 76, A 18, S\&A 6 & 47 & 4.4 & 87.5 \\
\hline & rhBMP 50 mg & & & & & \\
\hline Papanagiotou [43] 2014/P & $C D, F B G$ & 5 & S 40, A 20, I 40 & 32 & 4.0 & 80.0 \\
\hline & rhBMP $3.5 \mathrm{~g}$ & & & & & \\
\hline Kuroda [23] 2015/P & $C D$ & 10 & S 80, A 20 & 39.8 & 1.0 & 90.0 \\
\hline & rhFGF-2 $800 \mu \mathrm{g}$ & & & & & \\
\hline
\end{tabular}

$P$ prospective study, $R$ retrospective study, $R C T$ randomized clinical trial, $C D$ core decompression, $T R$ tantalum rod, $B M M N C$ bone marrow mononuclear cell, $B M C$ bone marrow cell, HA hydroxyapatite, FBG fibular bone graft, rhBMP recombinant human bone morphogenetic protein, ONFH osteonecrosis of the femoral head, $S$ steroid use, $A$ alcohol intake, $I$ idiopathic, $T$ trauma, NR not reported, SCD sickle cell disease 
for ONFH. In 19 joints from 18 patients, $3 / 6$ joints (50 \%) with precollapse ONFH and 8/13 joints (61.5\%) with early collapsed ONFH were reported to have undergone THA after an average of 8.5 months post-surgery [37].

\section{Cell transplantation}

In ONFH, progression of the necrotic area and occurrence of additional necrotic areas are extremely rare [38]. Therefore, regeneration of the necrotic bone to normal bone tissue could make it possible to cure ONFH. To regenerate the necrotic bone, there is a need to promote remodeling and angiogenesis as well as absorption of the necrotic bone. However, clinical results for free bone grafts do not indicate significant improvement over core decompression. Thus, a new treatment strategy has been attempted in which cell transplantation, such as autologous bone marrow mononuclear cells, was employed to regenerate the necrotic bone directly. As reported by Hernigou and Beaujean, bone marrow was taken from the iliac crest, and the mononuclear cell-containing fraction was separated using a cell centrifugal separation device [12]. The cells were injected into the necrotic bone area from the core decompression site that promotes the remodeling of cancellous bone regeneration and necrosis. After 8-18 years, only 94 of the 534 patients (17.6 \%) with precollapse ONFH were reported to have femoral head collapse [16]. In addition, Gangji et al. conducted a prospective double-blind study on 24 hips, in which core decompression and autologous bone marrow mononuclear cell transplantation combination were compared over 5 years. Progress and structural destruction of the subchondral bone were noted in 8 of the 11 joints $(72.7 \%)$ in the core decompression group and in 3 of the 13 joints (23.1\%) in the combination group [13]. Furthermore, in a systematic review, Papakostidis et al. reported that in the precollapse stage, core decompression with autologous bone marrow cell implantation into the femoral head is clinically effective and can improve survivorship of the femoral heads and reduce the need for THA [39]. Another systemic review by Lau et al. reported that cell therapy is considered a reliable regenerative approach to engraft more cells in the necrotic area and that further development of a method promoting differentiation is needed [40].

In combination with cell therapy, the use of artificial bone in the core decompression site has also been
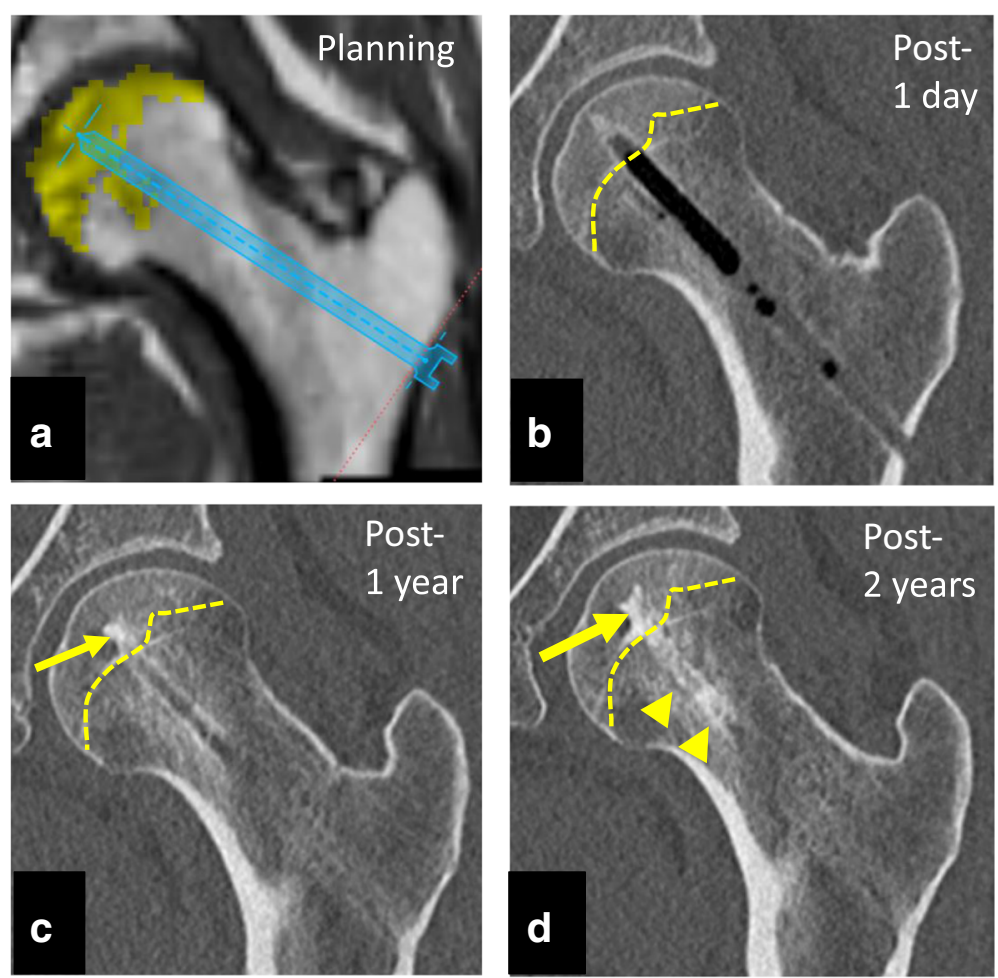

Fig. 3 Planning and representative computed tomography images. a A screenshot of the preoperative planning. b Coronal computed tomography image shows a bone defect at the drilling route and implanted region 1 day postoperatively. The yellow dashed line shows the border of the osteonecrotic area of the femoral head. $\mathbf{c}$ In contrast, apparent bone regeneration of the osteonecrotic area is observed at 1 year postoperatively (yellow arrow). The normal contour of the femoral head is maintained. $\mathbf{d}$ Apparent bone regeneration of the osteonecrotic area is observed in the implanted region (yellow arrow) and drilling route (yellow arrowheads) at 2 years postoperatively. Normal contour, thick trabecular bone, and bone regeneration of the drilling route can be observed 
developed. For instance, Civinini et al. reported that, with a combination of bone marrow cell transplantation and artificial bone, $5 / 30$ joints (16.6 \%) with precollapse ONFH and $3 / 7$ joints (42.8\%) with early collapsed ONFH further collapsed or progressed further an average of 20.6 months post-surgery [41]. Yamasaki et al. reported that 30 joints from 22 patients received transplanted bone marrow mononuclear cells with interconnected porous calcium hydroxyapatite into the femoral head; over an average of 29 months, 13 (43.3\%) experienced femoral head collapse [42].

Autologous bone marrow cell transplantation may be reliable in early-stage ONFH patients [12, 13, 16, 39, 40]. Ex vivo amplification of bone marrow cells has been proposed to increase the number of injected stem cells $[13-15,30]$.

\section{Growth factors}

Bone regeneration in joint areas using cell growth factors, another treatment approach, has become an important topic of research. Problems with protein therapy include an extremely short half-life and side effects with systemic or high-dose administration. The use of rhFGF2-impregnated gelatin hydrogel has the advantage of sustained release over rhFGF-2 solution because its biologic half-life period is short [21]. A slow-release system built around a bioabsorbable gelatin hydrogel enables local administration with excellent controlled release, greatly contributing to establishing practical use for protein therapy. Such factors useful for bone regeneration include transforming growth factor- $\beta$, bone morphogenetic protein (BMP), FGF-2, vascular endothelial growth factor, and insulin-like growth factor [2, 3, 9]. For ONFH, the use of BMP in combination with bone grafts has been reported. For example, Lieberman et al. co-administered rhBMP (50 $\mathrm{mg}$ ) with an allogeneic fibular graft after core decompression. Of 16 cases with precollapse ONFH, two $(12.5 \%)$ collapsed after an average of 53 months [17]. Moreover, Papanagiotou et al. co-administered rhBMP $3.5 \mathrm{mg}$ with an autologous fibular graft; of five cases with precollapse ONFH, one $(20 \%)$ experienced femoral head collapse over an average of 4 years [43].

In the field of bone and joint medicine, the angiogenic and osteogenic actions of rhFGF-2 have been the subject of numerous reports [21, 23, 24, 44, 45]. In particular, the use of gelatin hydrogel as a superior slow-release carrier has produced increased bone mass in areas of bone deficit [21]. Furthermore, rhFGF-2 administration produced rapid osteogenesis and increased bone mass in humans with lower leg fracture [44] and osteotomy surface [45]. A strategy using growth factors has also been proposed to treat ONFH. We reported the first clinical application of rhFGF-2-impregnated gelatin hydrogel for patients with precollapse stage of ONFH (Fig. 2) [24].
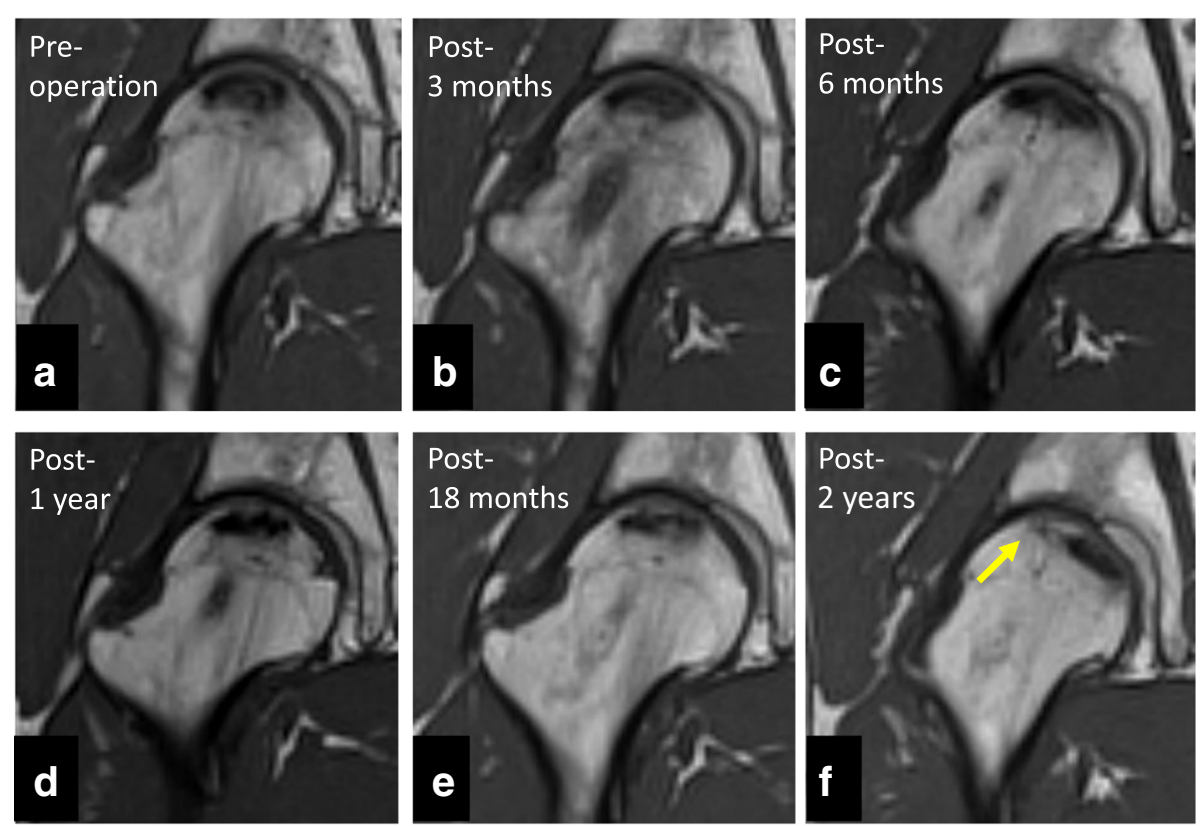

Fig. 4 Representative magnetic resonance images. a Preoperative coronal T1-weighted magnetic resonance imaging (MRI) showing osteonecrosis of the femoral head (ONFH) that occupied the weight-bearing portion and extended laterally to the acetabular edge. $\mathbf{b}-\mathbf{d}$ MRI scan of the ONFH area and the femoral neck region 6 months and 1 year postoperatively, showing continued low signal intensity, indicating the influence of the traumatic procedure. e MRI scan 18 months postoperatively, showing the first change of signal intensity at the drilling route. The drilling site at the femoral neck is changing to the normal signal intensity of the bone. $\mathbf{f}$ Most recent MRI scan 2 years postoperatively, showing almost normal signal intensity at the ONFH area. The area and size of ONFH decreased at the weight-bearing surface (yellow arrow) 
Ten patients with femoral heads up to precollapse stage 2 underwent a single local administration of $800-\mu \mathrm{g}$ rhFGF-2-impregnated gelatin hydrogel and followed up for 1 year. Primary outcomes included adverse events and complications. Secondary outcomes included changes in Harris Hip Scores, visual analog scale pain scores, and UCLA activity rating scores, radiological changes as determined via radiographs, computed tomography scans, and MRI of the hip joint. One-year short-term results of this pilot study indicated the approach was safe and feasible. During 1-year follow-up of 10 patients, there was only one case of femoral head collapse; however, this occurred in a hip with extensive necrosis. Stage progression and collapse did not occur in the other nine cases. The results of previous joint-preserving regenerative therapy-based core decompression are presented in Table 1.

The minimally invasive therapy (1-cm skin incision) attempted to prevent femoral head collapse through direct administration of rhFGF-2, which has both angiogenic and osteogenic actions. Computed tomography (Fig. 3) and recent MRI (Fig. 4) confirmed bone regeneration and reduction of the necrotic area. Additionally, hospitalization costs were dramatically reduced to $10 \%$ of that for THA. From an economic standpoint, avoiding the need for artificial joints could greatly reduce medical expenses. However, it is still unclear whether rhFGF-2 administration or conservative treatment has a better efficacy. Further studies with longer follow-up are needed to analyze and evaluate the survival rates of femoral heads treated with rhFGF-2 administration or conservative treatment.

\section{Conclusions}

The most recent regenerative therapy for ONFH has aimed to induce bone regeneration to prevent femoral head collapse. To develop the practical clinical application for regenerative ONFH therapies, suitable sources, including cell sources, artificial materials, specific proteins, or combinations thereof, must be identified. With the use of various regenerative therapies, including cell therapy, implants, and recombinant growth factors, the treatment for ONFH will reach a turning point in the near future.

\section{Consent for publication}

This study was performed in accordance with the declaration of Helsinki. The entire treatment protocol was approved by the Ethics Committee of Kyoto University Graduate School and Faculty of Medicine. Written informed consent was obtained from all participants involved in the study. The clinical study reported herein was registered to the public Japanese clinical trials registry (UMIN000009250).

\section{Abbreviations}

BMP: bone morphogenetic protein; MRI: magnetic resonance imaging; $\mathrm{OA}$ : osteoarthritis; ONFH: osteonecrosis of the femoral head;

rhFGF: recombinant human fibroblast growth factor; THA: total hip arthroplasty.

\section{Competing interests}

The authors declare that they have no competing interests.

\section{Authors' contributions}

YK, SM, and HA conceived and designed the experiments. YK and HA performed the experiments. KY, SM, and HA contributed to the writing of the manuscript. All authors read and approved the final manuscript.

\section{Acknowledgements}

We thank T. Ito-Ihara and R. Aasda for the clinical trial design and management.

\section{Funding}

This work was supported in part by grants from The Uehara Memorial Foundation (to HA).

\section{Author details}

${ }^{1}$ Department of Orthopaedic Surgery, Graduate School of Medicine, Kyoto University, Shogoin, Kawahara-cho 54, Sakyo-ku, Kyoto 606-8507, Japan.

${ }^{2}$ Department of Orthopaedic Surgery, Gifu University, Gifu, Japan.

Received: 15 January 2016 Accepted: 2 April 2016

Published online: 25 April 2016

\section{References}

1. Fukushima W, Fujioka M, Kubo T, Tamakoshi A, Nagai M, Hirota Y. Nationwide epidemiologic survey of idiopathic osteonecrosis of the femoral head. Clin Orthop Relat Res. 2010;468(10):2715-24.

2. Moya-Angeler J, Gianakos AL, Villa JC, Ni A, Lane JM. Current concepts on osteonecrosis of the femoral head. World J Orthop. 2015;6(8):590-601. 18.

3. Mont MA, Cherian JJ, Sierra RJ, Jones LC, Lieberman JR. Nontraumatic osteonecrosis of the femoral head: where do we stand today? A ten-year update. J Bone Joint Surg Am. 2015;97(19):1604-27.

4. Seamon J, Keller T, Saleh J, Cui Q. The pathogenesis of nontraumatic osteonecrosis. Arthritis. 2012;2012:601763.

5. Johnson AJ, Mont MA, Tsao AK, Jones LC. Treatment of femoral head osteonecrosis in the United States: 16-year analysis of the Nationwide Inpatient Sample. Clin Orthop Relat Res. 2014;472(2):617-23.

6. Mont MA, Carbone JJ, Fairbank AC. Core decompression versus nonoperative management for osteonecrosis of the hip. Clin Orthop Relat Res. 1996:324:169-78.

7. Hernigou P, Ooignard A, Nogier A, Manicom O. Fate of very small asymptomatic stage-I osteonecrotic lesions of the hip. J Bone Joint Surg Am. 2004;86:2589-93.

8. Jawad MU, Haleem AA, Scully SP. In brief: Ficat classification: avascular necrosis of the femoral head. Clin Orthop Relat Res. 2012;470(9):2636-9.

9. Mont MA, Jones LC, Einhorn TA, Hungerford DS, Reddi AH. Osteonecrosis of the femoral head-potential treatment with growth and differentiation factors. Clin Orthop Relat Res. 1998;355:S314-35.

10. Mont MA, Jones LC, Hungerford DS. Nontraumatic osteonecrosis of the femoral head: ten years later. J Bone Joint Surg Am. 2006;88:1117-32.

11. Bakhshi H, Rasouli MR, Parvizi J. Can local Erythropoietin administration enhance bone regeneration in osteonecrosis of femoral head? Med Hypotheses. 2012;79:154-6.

12. Hernigou P, Beaujean F. Treatment of osteonecrosis with autologous bone marrow grafting. Clin Orthop Relat Res. 2002:405:14-23.

13. Gangji V, De Maertelaer V, Hauzeur JP. Autologous bone marrow cell implantation in the treatment of non-traumatic osteonecrosis of the femoral head: five year follow-up of a prospective controlled study. Bone. 2011;49:1005-9.

14. Rastogi S, Sankineani SR, Nag HL, Mohanty S, Shivanand G, Marimuthu K, et al. Intralesional autologous mesenchymal stem cells in management of osteonecrosis of femur: a preliminary study. Musculoskelet Surg. 2013;97:223-8.

15. Houdek MT, Wyles CC, Martin JR, Sierra RJ. Stem cell treatment for avascular necrosis of the femoral head: current perspectives. Stem Cells Cloning. 2014;7:65-70.

16. Hernigou P, Poignard A, Zilber S, Rouard H. Cell therapy of hip osteonecrosis with autologous bone marrow grafting. Indian J Orthop. 2009;43:40-5. 
17. Lieberman JR, Conduah A, Urist MR. Treatment of osteonecrosis of the femoral head with core decompression and human bone morphogenetic protein. Clin Orthop Relat Res. 2004;429:139-45.

18. Sun W, Li Z, Gao F, Shi Z, Zhang Q, Guo W. Recombinant human bone morphogenetic protein-2 in debridement and impacted bone graft for the treatment of femoral head osteonecrosis. PLoS One. 2014;9:e100424.

19. Manggold J, Sergi C, Becker K, Lukoschek M, Simank HG. A new animal model of femoral head necrosis induced by intraosseous injection of ethanol. Lab Anim. 2002;36:173-80.

20. Boss $\mathrm{JH}$, Misselevich I. Osteonecrosis of the femoral head of laboratory animals: the lessons learned from a comparative study of osteonecrosis in man and experimental animals. Vet Pathol. 2003;40:345-54.

21. Tabata Y, Yamada K, Miyamoto S, Nagata I, Kikuchi H, Aoyama I, et al. Bone regeneration by basic fibroblast growth factor complexed with biodegradable hydrogel. Biomaterials. 1998;19:807-15.

22. Jones LC, Tucci MA, Haile A, Wang D. Animal models of corticosteroidassociated bone diseases. In: Koo K-H, Mont MA, Jones LC, editors. Osteonecrosis. Heidelberg, New York, Dordrecht, London: Springer; 2014. p. 493-505.

23. Kuroda Y, Akiyama H, Kawanabe K, Tabata Y, Nakamura T. Treatment of experimental osteonecrosis of the hip in adult rabbits with a single local injection of recombinant human FGF-2 microspheres. J Bone Miner Metab. 2010;28:608-16

24. Kuroda Y, Asada R, So K, Yonezawa A, Nankaku M, Mukai K, et al. A pilot study of regenerative therapy using controlled release of rhFGF-2 for patients with precollapse osteonecrosis of the femoral head. Int Orthop. 2015; doi: 10.1007/s00264-015-3083-1

25. Rijnen WH, Gardeniers JW, Westrek BL, Buma P, Schreurs BW. Sugioka's osteotomy for femoral-head necrosis in young Caucasians. Int Orthop. 2005;29:140-4.

26. Koo KH, Kim R, Ko GH, Song HR, Jeong ST, Cho SH. Preventing collapse in early osteonecrosis of the femoral head. A randomised clinical trial of core decompression. J Bone Joint Surg (Br). 1995;77(6):870-4.

27. Soohoo NF, Vyas S, Manunga J, Sharifi H, Kominski G, Lieberman JR. Cost-effectiveness analysis of core decompression. J Arthroplasty. 2006;21:670-81.

28. Steinberg ME, Steinberg DR. Historical perspective. In: Koo K-H, Mont MA, Jones LC, editors. Osteonecrosis. Heidelberg, New York, Dordrecht, London: Springer; 2014. p. 3-15.

29. Jauregui JJ, Banerjee S, Kapadia BH, Cherian JJ, Issa K, Mont MA. Principles of bone grafting for osteonecrosis of the hip. In: Koo K-H, Mont MA, Jones LC, editors. Osteonecrosis. Heidelberg, New York, Dordrecht, London: Springer; 2014. p. 307-13.

30. Aoyama T, Goto K, Kakinoki R, Ikeguchi R, Ueda M, Kasai Y, et al. An exploratory clinical trial for idiopathic osteonecrosis of femoral head by cultured autologous multipotent mesenchymal stromal cells augmented with vascularized bone grafts. Tissue Eng Part B Rev. 2014;20(4):233-42.

31. Chen $\mathrm{CH}$, Chang JK, Lai KA, Hou SM, Chang CH, Wang GJ. Alendronate in the prevention of collapse of the femoral head in nontraumatic osteonecrosis: a two-year multicenter, prospective, randomized, double-blind, placebocontrolled study. Arthritis Rheum. 2012;64:1572-8.

32. Wang C, Peng J, Lu S. Summary of the various treatments for osteonecrosis of the femoral head by mechanism: a review. Exp Ther Med. 2014;8(3):700-6.

33. Marker DR, Seylee TM, McGrath MS, Delanois RE, Ulrich SD, Mont MA. Treatment of early stage osteonecrosis of the femoral head. J Bone Joint Surg Am. 2008;90:175-87.

34. Tsao AK, Roberson JR, Christie MJ, Dore DD, Heck DA, Robertson DD, et al Biomechanical and clinical evaluations of a porous tantalum implant for the treatment of early-stage osteonecrosis. J Bone Joint Surg Am. 2005;87(S2):22-7.

35. Veillette CJ, Mehdian H, Schemitsch EH, McKee MD. Survivorship analysis and radiographic outcome following tantalum rod insertion for osteonecrosis of the femoral head. J Bone Joint Surg Am. 2006;88(S3):48-55.

36. Floerkemeier $T$, Thorey $F$, Daentzer $D$, Lerch $M$, Klages $P$, Windhagen $H$, et al. Clinical and radiological outcome of the treatment of osteonecrosis of the femoral head using the osteonecrosis intervention implant. Int Orthop. 2011;35(4):489-95.

37. Yu PA, Peng KT, Huang TW, Hsu RW, Hsu WH, Lee MS. Injectable synthetic bone graft substitute combined with core decompression in the treatment of advanced osteonecrosis of the femoral head: a 5-year follow-up. Biomed J. 2015;38(3):257-61

38. Nam KW, Kim YL, Yoo JJ, Koo KH, Yoon KS, Kim HJ. Fate of untreated asymptomatic osteonecrosis of the femoral head. J Bone Joint Surg Am. 2008;90(3):477-84.
39. Papakostidis C, Tosounidis TH, Jones E, Giannoudis PV. The role of "cell therapy" in osteonecrosis of the femoral head. Acta Orthop. 2015;29:1-7.

40. Lau RL, Perruccio AV, Evans HM, Mahomed SR, Mahomed NN, Gandhi R. Stem cell therapy for the treatment of early stage avascular necrosis of the femoral head: a systematic review. BMC Musculoskelet Disord. 2014;15:156.

41. Civinini R, De Biase P, Carulli C, Matassi F, Nistri L, Capanna R, et al. The use of an injectable calcium sulphate/calcium phosphate bioceramic in the treatment of osteonecrosis of the femoral head. Int Orthop. 2012;36(8):1583-8.

42. Yamasaki T, Yasunaga Y, Ishikawa M, Hamaki T, Ochi M. Bone-marrowderived mononuclear cells with a porous hydroxyapatite scaffold for the treatment of osteonecrosis of the femoral head: a preliminary study. J Bone Joint Surg (Br). 2010;92(3):337-41.

43. Papanagiotou M, Malizos KN, Vlychou M, Dailiana ZH. Autologous (nonvascularised) fibular grafting with recombinant bone morphogenetic protein-7 for the treatment of femoral head osteonecrosis: preliminary report. Bone Joint J. 2014;96-B(1):31-5.

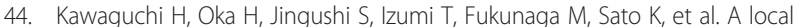
application of recombinant human fibroblast growth factor 2 for tibial shaft fractures: a randomized, placebo-controlled trial. J Bone Miner Res. 2010;25:2735-43.

45. Kawaguchi $H$, Jingushi $S$, Izumi T, Fukunaga M, Matsushita T, Nakamura T, et al. Local application of recombinant human fibroblast growth factor-2 on bone repair: a dose-escalation prospective trial on patients with osteotomy. J Orthop Res. 2007:25:480-7.

\section{Submit your next manuscript to BioMed Central and we will help you at every step:}

- We accept pre-submission inquiries

- Our selector tool helps you to find the most relevant journal

- We provide round the clock customer support

- Convenient online submission

- Thorough peer review

- Inclusion in PubMed and all major indexing services

- Maximum visibility for your research

Submit your manuscript at www.biomedcentral.com/submit
Biomed Central 